Políticas Públicas de Informação no Contexto da Inclusão e Gestão da Informação: uma análise sobre as políticas públicas da Secretaria Municipal de Educação de Juazeiro do Norte - CE, de autoria de Naira Michelle Alves Pereira e Jonathas Luiz Carvalho Silva, tem por objetivo investigar percepções referentes às políticas públicas de informação no contexto das políticas públicas de educação da Secretaria Municipal de Educação de Juazeiro do Norte/CE. A metodologia do presente artigo foi estabelecida quanto aos fins como sendo de cunho exploratório e descritivo, pois se busca estabelecer uma possível interpolação das políticas públicas de informação no âmbito das políticas públicas de educação existentes na Secretaria Municipal de Educação de Juazeiro do Norte/CE. Quanto aos meios, a pesquisa classifica-se como sendo bibliográfica e documental, uma vez que foi realizada revisão da literatura para construção do referencial teórico e utilizados documentos disponibilizados nos portais de comunicação do governo federal, estadual e municipal, para descrever e analisar as políticas públicas em estudo. No que se refere à natureza dos dados, sua análise foi realizada por meio de uma abordagem qualitativa a partir da aplicação de entrevistas junto aos coordenadores responsáveis pelo gerenciamento das políticas públicas em estudo. Considera-se que o município de Juazeiro do Norte/CE precisa de investimento por parte do governo em infraestrutura informacional e tecnológica no campo educacional, que garantam o melhor desempenho dos significados informacionais percepcionados no âmbito dessas políticas educacionais.

Empréstimo de livros eletrônicos, redes sociais e a proteção de dados dos usuários, de Liliana Giusti Serra, discorre sobre a questão da proteção de dados e privacidade dos usuários nas bibliotecas a partir do empréstimo de livros eletrônicos realizado pela parceria OverDrive-Amazon e o uso de redes sociais. É realizado um breve panorama dos normativos relativos à confidencialidade de dados por parte das bibliotecas nos Estados Unidos, países da Europa e a situação brasileira. Finaliza discorrendo sobre a importância da utilização de livros eletrônicos e redes sociais pelas bibliotecas, ressaltando apenas que esse uso seja realizado garantindo a preservação e confidencialidade dos dados pessoais dos usuários, utilizando-se das informações coletadas, mas revertendo-as em ofertas de serviços e divulgação dos acervos.

Elisa Cristina Delfini Correa, Divino Ignácio Ribeiro Júnior e Jordan Pauleski Juliani são os autores de Periódicos Científicos Interativos em Ciência da Informação e Biblioteconomia: Uma Utopia Possível, pesquisa que investiga a aceitabilidade da introdução de aspectos de interatividade da web 2.0 em artigos científicos na área de Biblioteconomia e Ciência da Informação pela sua comunidade de autores. Os dados foram coletados através de questionário enviado eletronicamente a uma amostra de autores que publicaram artigos em revistas da área. Os resultados apontam para o 
interesse na introdução de características como hipertextualidade, hipermidiaticidade e interatividade, bem como sua disposição em publicar artigos em uma revista dessa natureza.

\section{Sistema de Registro de Termos: Proposta de Contribuição à Pesquisa} Terminológica Temática, de autoria de José Carlos Mardegan e Brigida Maria Nogueira Cervantes, usa a pesquisa terminológica temática é o ponto de partida para a criação de vocabulários controlados. O estudo apresenta proposta de construção de um sistema de registro de termos, com base em um banco de dados relacional, para automatizar parte das etapas da pesquisa terminológica. Para concretizar a experiência, foi necessária a elaboração de uma pesquisa terminológica temática que serviu de teste para a ferramenta proposta. Este estudo tem natureza exploratória, e o corpus da coleta foi composto por vinte duas referências, incluindo os dicionários e glossários usados na validação dos termos. A fundamentação teórica foi direcionada à compreensão dos conceitos capazes de explicar os pressupostos envolvidos, tanto na pesquisa terminológica, quanto na construção do sistema de registro de termos. Com a pesquisa, coletaram-se cento e onze termos, destes, oitenta foram validados, obtendo-se um índice de validação de $72 \%$, número considerado relevante para o contexto do trabalho. $\mathrm{O}$ sistema de registro de termos demonstrou-se eficaz, apresentando soluções de armazenamento e de recuperação dos termos cadastrados, por intermédio de várias opções de buscas. $\mathrm{O}$ estudo enunciou procedimentos visando à continuidade do projeto, por meio da criação de outros mecanismos para a manutenção da base de dados, disponibilizando-a, inclusive, para a comunidade, na internet.

Já Rita de Cássia do Vale Caribé e Evelaine Santos de Oliveira são as responsáveis pela pesquisa qualitativa realizada junto aos usuários do Tesauro de Contas que integra o sistema Processo Eletrônico (e-TCDF), do Tribunal de Contas do Distrito Federal, Brasil. Foram realizadas 20 entrevistas orientadas, utilizando perguntas abertas e fechadas de múltipla escolha. Esta pesquisa possibilitou a caracterização das principais dificuldades enfrentadas pelos usuários, a coleta de sugestões que permitem o aprimoramento do instrumento, bem como a compreensão quanto à utilização do Tesauro pelos usuários, por meio da qual foi detectada a necessidade de treinamento e de aprimoramento no sistema. O artigo se chama Avaliação do tesauro do Tribunal de Contas do Distrito Federal a partir dos usuários.

Francisco Carlos Paletta e Bárbara Pelissaro são os responsáveis por Estudo de Usuários e Modelos de Busca da Informação, que trata a importância de investir no uso das tecnologias e nos profissionais da informação, área que representa status avançado na evolução da sociedade e, na mesma medida, investir em estudos voltados à informação e à gestão do conhecimento, para entender as diferentes necessidades de quem anseia por informação, as dificuldades de quem a procura e os caminhos a trilhar para facilitar ou tornar menos árdua a busca pelo conhecimento. 
Em Trajetória Histórica das Bibliotecas e o Desenvolvimento dos Serviços Bibliotecários: da Guarda Informacional ao Acesso, Jorge Santa-Anna traz à baila o desenvolvimento da instituição biblioteca e os reflexos acarretados à prática do bibliotecário, cujos fazeres se adentram a novas concepções paradigmáticas: do armazenamento à acessibilidade. Partindo dos quatro grandes estágios pelos quais passaram as bibliotecas ao longo dos tempos: laicização, democratização, especialização e socialização, seu artigo objetiva refletir a trajetória histórica e o desenvolvimento dos serviços bibliotecários, com vistas à evolução da tecnologia, especificamente com o advento do espaço digital, consumado a partir do desenvolvimento da internet, o que aponta o surgimento da biblioteca virtual na sociedade contemporânea. Metodologicamente, foi utilizada a revisão literária em artigos científicos publicados em revistas brasileiras de biblioteconomia e livros que retratam a trajetória histórica da biblioteca e dos registros de informação. Em linhas gerais, os resultados apontam a necessidade de o bibliotecário ser flexível a mudanças, utilizando as novas tecnologias para reconstruir as práticas bibliotecárias, com maior preocupação para o usuário e suas necessidades, o que confirma a mudança de perfil desse profissional: de guardião da informação a disseminador.

Mário Gouveia Junior em $O$ pensamento de baumaniano e os paradigmas de mediação da informação, pretende verificar se a lógica baumaniana que trata do par de conceitos Liberdade e Segurança, nas relações entre indivíduo e sociedade, pode ser aplicada às relações de mediação e custódia vivenciadas pelos Sistemas de Informação. Trata-se de uma revisão de literatura e apresenta como resultados a perspectiva de que o emergente Paradigma Pós-custodial pode ser uma resposta ao dilema entre a preservação e o acesso à informação. Nesse sentido, a digitalização de conteúdos informacionais, naturalmente, seguidas de sua preservação em plataformas que se disponham a seguir padrões de armazenamento e recuperação de informação confiáveis pode representar a medida para que se possa obter o sucesso entre os pares de ambivalências paradigmáticas presentes nos serviços de mediação: custódia-acesso e segurança-liberdade de informação.

Em Revisitando a Preservação na Perspectiva da Ciência da Informação: Aproximações Conceituais, de Danilo Formenton, Luciana de Souza Gracioso e Fabiano Ferreira de Castro, vemos que a preservação digital é hoje o caminho mais adequado para salvaguardar a memória e o acesso aos conteúdos informacionais em ambientes digitais. Nesse sentido, as instituições tendem a buscar ações de divulgação, de cooperação e de trocas de experiências sobre os processos e as metodologias de preservação digital. Este trabalho propôs ampliar a compreensão conceitual quanto ao processo de preservação digital e de suas implicações, através da identificação e da descrição dos conceitos de preservação digital e objeto digital, dos requisitos e das principais estratégias neste domínio. Para isso, uma pesquisa exploratória foi realizada, de natureza bibliográfica e documental, pautando-se no método de Revisão de Literatura Sistemática, a fim de compreender, segundo a literatura científica da área de Ciência da Informação, as discussões acerca da preservação digital advindas do Brasil, da América 
do Norte e da Europa. A partir dos estudos, verificou-se que a preservação digital é um processo que consiste essencialmente em assegurar a preservação do acesso de modo utilizável ao conteúdo dos objetos digitais por longo período. A complexidade em seu desenvolvimento está inteiramente associada às características do meio digital e à natureza dos próprios objetos que procura preservar. Em relação às estratégias existentes, a migração configurou-se como a mais adequada para o contexto da grande maioria das instituições que pretendem implantar um processo de preservação digital. Constatou-se que o tema ainda é recente e carece de mais estudos da comunidade da Biblioteconomia e da Ciência da Informação, no contexto científico nacional, evidenciando assim a necessidade de mais pesquisas sobre a preservação digital, sobremaneira, na identificação de processos e de metodologias para a preservação de objetos digitais em ambientes informacionais.

Já em $O$ desenvolvimento da Competência Informacional nas crianças a partir da literatura infantil, Djuli Machado De Lucca, Clarice Fortkamp Caldin e João Primo Ramirez Righi realizam uma reflexão acerca da prática de leitura de literatura infantil enquanto forma de desenvolver a Competência Informacional nas crianças e abordam o papel do bibliotecário e da biblioteca escolar neste contexto. Para tanto, o trabalho realiza pesquisa exploratória (do ponto de vista dos objetivos) e bibliográfica (do ponto de vista dos procedimentos técnicos). Discorre sobre a Competência Informacional enquanto movimento que estimula o uso crítico e reflexivo da informação. Aborda a primeira fase de desenvolvimento da Competência Informacional, entendida como letramento informacional, que envolve o desenvolvimento de habilidades básicas relacionadas aos suportes informacionais, e que acontece geralmente na infância. Apresenta a leitura de literatura infantil como forma de propiciar o desenvolvimento da Competência Informacional nas crianças, pois apresenta o maravilhoso como forma de entender a realidade. Aponta o bibliotecário e a biblioteca como propulsores do desenvolvimento deste conjunto de habilidades. Ao fim, infere que a função social da literatura infantil consiste no desenvolvimento da Competência Informacional nas crianças. Advoga que a biblioteca deve construir um novo paradigma educacional e o bibliotecário deve acoplar à função de técnico e gestor da informação, a função de educador. Finaliza com sugestões de mudança de comportamento do bibliotecário, a fim de que o mesmo possa participar de forma dinâmica, do letramento informacional, fomentando a leitura de textos literários infantis.

Finalmente, em Proposta de Instrumento Para Avaliação da Gestão Editorial das Revistas Científicas Brasileiras em Educação Física e Ciências do Esporte, de autoria de Ivone Job, Silvana e Vilodre Goellner, vemos a proposta e aplicação de um instrumento para avaliar a gestão editorial das revistas com base em determinados conceitos, categorias e unidades de análise. O instrumento foi aplicado em revistas da área de educação física e ciências do esporte, mas poderá ser utilizado em revistas das demais áreas. A pesquisa é de cunho quantitativo, bibliométrico e identifica critérios mais importantes para avaliar a gestão editorial das revistas que foram agrupados em cinco

n.1


categorias: qualidade editorial, difusão, normalização, processo de arbitragem e autoria. Para cada categoria há determinados indicadores, especificados segundo sua definição, aplicação e pontuação. Das 12 revistas analisadas, 8 atingiram $80 \%$ dos critérios exigidos. Nos resultados são apresentados os pontos fortes do conjunto de revistas, suas características e recomendações aos editores e comitês editoriais. Se as categorias normalização e qualidade editorial estão bem pontuadas no conjunto, o mesmo não se pode dizer das de difusão, processo de arbitragem e autoria.

Tenham uma ótima leitura!

Danielle Thiago Ferreira

Gildenir Carolino Santos

Editores Científicos

Rev. digit. bibliotecon. cienc. inf.

Janeiro/2015 